\title{
The Design of Electric Bicycle Charging Station Based on Solar Photovoltaic Power
}

\author{
Huaizhong Chen \\ Zhejiang Industry Polytechnic College, Shaoxing, China \\ Chz702@163.com
}

Keywords: Combination energy; Storage device; DC bus; Converter; Solar photovoltaic

\begin{abstract}
With the currently for DC micro grid of exploration and research, this paper puts forward the solar photovoltaic electric bicycle charging station research and design based on. It is the application of the solar photovoltaic power generation power through the DC bus to the electric bicycle load, through the combination of energy storage devices to regulate the DC bus. The whole system consists of solar array, reservoir assemblage can device, a DC bus, electric bicycle load and power electronic interface and other components, the power electronic interface including solar cell array and DC bus interface, reservoir assemblage can load device and DC bus interface and the DC bus and electric bicycle interface. The solar photovoltaic power generation is applied to the electric bicycle load through the DC bus, and the voltage regulation of the DC bus bar through the energy storage device has good effect.
\end{abstract}

\section{Introduction}

The current city of more and more vehicles, vehicles in the process of running a lot of waste gas, the ring environment caused great harm to people's health has also caused harm, at the same time, the increase of vehicles also make the city traffic congestion, give people's travel safety has brought hidden danger. Traffic congestion is each city a persistent ailment. Under this background, and in recent years battery technology development, the electric bicycle in the city operation has the very popular and its lightweight body, low prices can quickly enter the market, effectively alleviate the pressure of traffic and protect the environment. But there are still a lot of problems on the use of electric bicycles, such as greater power consumption, the electric bicycle battery capacity caused by driving distance is limited. Electric bicycle is a common use of the city electric network, although the cost is low, but the road, car park and other places do not have electric bicycle charging conditions. Therefore, the use of solar energy, the establishment of electric bicycle charging station is very necessary. For example, in the shed or gas station's top, the shop on solar panels, cannot occupy large area, can also be environmentally friendly, save the city electricity.

\section{Design Energy Storage Device}

The super capacitor is mainly formed by the adsorption and desorption of ions in the electric double layer on the electrode / electrolyte interface. Rapid electrochemical reactions on the electrode surface to achieve the storage and release of energy. The electrode is not involved in the whole process of charging and discharging. Structure changes, also does not produce chemical reaction, the energy storage process is reversible. In the ideal state, there is no occurrence of the electrode. Determination of the reaction rate and the limit of the electrode life of the related changes of the active material.

Therefore, the theory of super capacitor should have High power density and cycle density. Research and design of a photovoltaic power generation system, our biggest goal is to effectively use the solar array Electric energy. And the most important and basic technical indicators of the solar photovoltaic power generation is the charging and discharging efficiency of the combined energy storage device. Solar photovoltaic power generation has the characteristics of intermittent and random nature, this intermittent and random power supply will be straight. The safety, stability, power quality and other aspects of the flow load are impact and influence. The energy storage 
device is the combination of the super capacitor and the storage battery, and is not used for storing the battery as the energy storage device. The intermittent power supply can make the output power of the intermittent power supply tend to be stable, and the impact on the DC load is reduced.

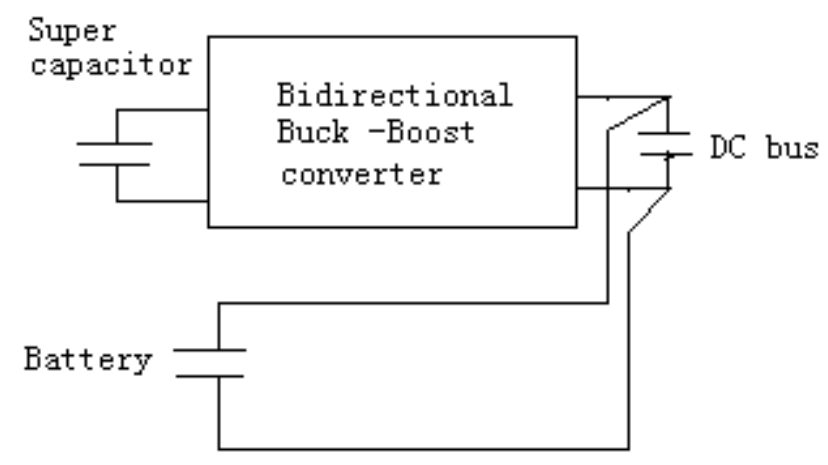

(a)

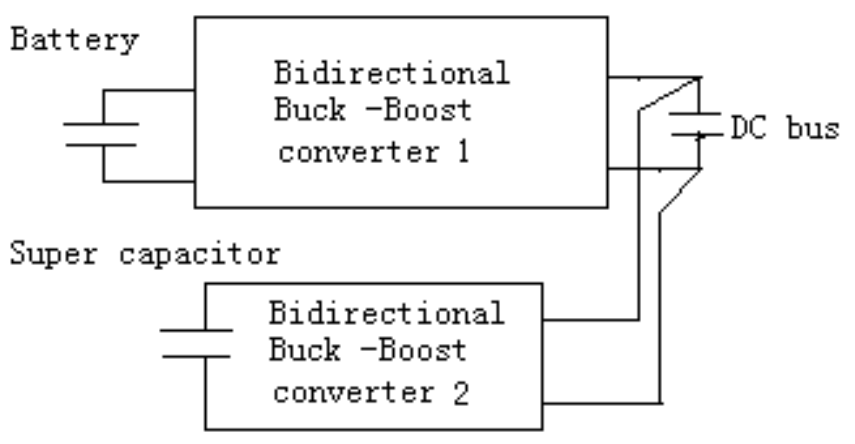

(b)

Figure 1. Structure of combined energy storage device

In Fig. 1. (a), the battery pack is directly connected to the DC bus, which supports the DC bus voltage. In Fig. 1 (b), a DC/DC bidirectional converter is added between the battery pack and the DC bus. In order to enable the energy flow between the battery pack and the super capacitor group, the energy storage device and the solar cell board are more flexible. In this paper, the circuit structure is used in Fig. 1 (b).

The combined energy storage device has 2 kinds of devices, such as a super capacitor and a storage battery, and the battery and the super capacitor are fully played. Their respective advantages to enhance the performance of the energy storage device, so that the whole system is stable. The function of the combined energy storage device is as follows:

First, there is a maximum power tracking DC/DC converter, you can track the maximum power of the solar cell array.

Second, the use of DC bus as an intermediate energy conversion link, the solar cell array directly to the power supply to the electric bicycle load or stored in the combined energy storage device reduces the electric energy of the photovoltaic cell to the middle conversion of the load end. Number of times. The output power of the photovoltaic cell can be fully utilized, and the electric energy loss can be reduced. At the same time, the middle of the power electronics control of the converter circuit is relatively small, it is conducive to reduce the cost of the system.

Third, the combined energy storage device adopts the combination of the storage battery and the super capacitor, and the battery is not used alone. By using the advantage of the super capacitor, the whole energy storage link is more flexible and changeable, and better adapt to the changeable solar energy. Source input, so that the DC link voltage stability. So the architecture is a kind of system frame which can efficiently utilize the output power of photovoltaic cells. 


\section{Control Method}

MPPT control method. Photovoltaic batteries can constantly adjust the working point according to surrounding environment light intensity and working temperature through certain control means. Therefore, it can be always operated on the maximum power point. It is called Maximum Power Point Tracking (MPPT). The cost of solar panels is still high at present. MPPT technology can be used for significantly improving the efficiency of photovoltaic power generation system and reducing equipment investment.

Output power of the photovoltaic battery can be adjusted by changing the duty cycle of DC/DC conversion device, thereby changing the working point of the photovoltaic battery. The output voltage value of the photovoltaic battery is directly affected by duty ratio change. Maximum power point tracking also can be comprehended from the aspect of impedance matching principle: circuit theory knowledge shows that when power supply impedance is equivalent to the load impedance, the output power of the power supply is the maximum. We can regard photovoltaic battery as DC power supply with internal resistance, and its internal resistance can be constantly changed with environment. DC/DC converter changes the duty ratio, which is equal to change of load equivalent impedance. When their impedances are equal, the photovoltaic battery reaches the maximum power working point.

CVT control method. The basic thoughts of constant voltage tracking method is to control the output voltage of photovoltaic cell at a fixed place; the output voltages of photovoltaic arrays are all distributed around this voltage. At this time, the photovoltaic array approximately works at the maximum power point. The constant voltage tracking output characteristics is shown as Fig. 2.

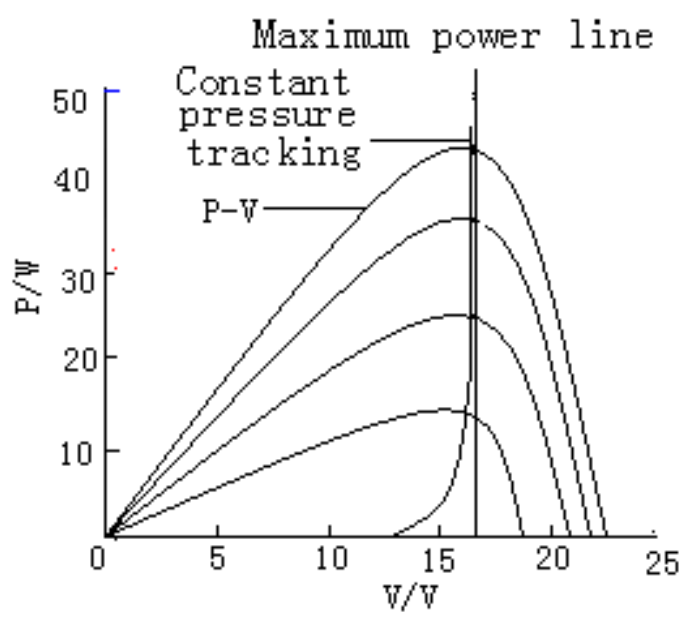

Figure 2. Constant Voltage Tracking output characteristics

It can be seen from the figure, when the temperature is constant, under different light intensity of solar panels maximum power point almost in the same vertical line on both sides of the adjacent, which may the maximum power line approximately as $\mathrm{V}$ voltage constant of a root vertical line, the photovoltaic panels to a fixed voltage. Constant pressure tracking method is an approximate maximum power tracking method.

The design idea and structure of constant voltage method is simple, easy to control, easy to implement, high reliability and stability.

\section{Energy Control}

Considering the fluctuation of the power of the solar power generation and the characteristics of the energy storage device, the combined energy storage device can be determined. The idea of the energy control: the super capacitor bears the frequent fluctuation of the energy storage load P1, which can make full use of the super capacitor. The capacitor has the advantages of high power output capability, long cycle life, fast response speed, and can effectively avoid the super power. 
The storage battery can be less than the smooth part of the energy storage load, which can reduce the frequent charging and discharging caused by frequent charging and discharging. The charging and discharging process of the battery is improved, the battery life is prolonged, and the energy storage technology is improved. Economy of. In order to distinguish the frequent fluctuation part and the smooth part of the energy storage load P1, the method of moving average filter is adopted. In this paper, the structure and control strategy of the hybrid power supply system of the solar photovoltaic power generation system with super capacitor and storage battery as a hybrid energy storage system is studied. Hybrid energy storage system by bi-directional converter control is always in the optimization of the charge and discharge state, guarantee the stable operation of the load; and through the bi-directional converter effectively control the charging current of the battery, so that the charging current remained at the maximum acceptable charging current, prolonging the service life of the battery, battery quick charging.

\section{Conclusions}

In this paper, the structure and control strategy of the hybrid power supply system of the solar photovoltaic power generation system with super capacitor and storage battery as a hybrid energy storage system is studied. Hybrid energy storage system by bi-directional converter control is always in the optimization of the charge and discharge state, guarantee the stable operation of the load; and through the bi-directional converter effectively control the charging current of the battery, so that the charging current remained at the maximum acceptable charging current, prolonging the service life of the battery, battery quick charging.

\section{Acknowledgements}

This work is supported by scientific research funded project of Science Technology Department of Zhejiang Province (2015C31128).

\section{References}

[1] Sun K, Zhang L, Xing Y, IEEE Transactions on Power Electronics, Vol.26 (2011) No.10p.3032-3045.

[2] Si Jiang, The 2011 Twenty-Sixth Annual IEEE on Applied Power Electronics Conference and Exposition, 2011:401-406.

[3] Vulturescu, S.Butterbach, Electrical Machines Conference, Vol.21 (2010), No.1, p.147-152.

[4] Linzen D, Buller S, Karden E, et al. IEEE Trans on Industry Applications, Vol.41 (2014), No.5, p. 1135-1141.

[5] Zhang Jiancheng, International Conference on Electronics and Drivers systems, Vol.3 (2012), No.2, p.1366-1369.

[6] Nowak M, Hildebrandt J, Luniewski P, 35th Annual IEEE Power Electronics Conference, Vol.3 (2011), No.2, p. 234-244.

[7] Tao H, Kotsopoulos A, Duarte J L, IEEE 36th on Power Electronics Specialists Conference, Vol.3 (2004), No.3, p. 2487-2493.

[8] Hang Y, Master degree thesis of Chongqing University, 2011, pp.567-475.

[9] Mellor P H, Schofield N, IEE Seminar 11 on Electric, Hybrid and Fuel Cell Vehicles. Sheffield Univ England, Vol.17 (2012) No.8, p1-5.

[10]Junseok Song, IEEE Sustainable Energy, Vol.17 (2013) No.2p.491-499. 